\title{
A novel multimedia device ability matching technique for ubiquitous computing environments
}

\author{
Jianwei Zhang ${ }^{1}$, Pan Deng ${ }^{2}$, Jiafu Wan ${ }^{3 *}$, Biying Yan ${ }^{2}$, Xiaohui Rong ${ }^{1}$ and Feng Chen ${ }^{1}$
}

\begin{abstract}
In wireless multimedia sensor networks (WMSNs), wirelessly interconnected devices are able to ubiquitously retrieve multimedia contents such as video and audio streams from the environment. However, since WMSN applications are large-scale, dynamic and highly concurrent, how to achieve both effective multimedia device resource management and collaborative task scheduling simultaneously becomes a serious problem. In this paper, using the hierarchical modeling technique, we first propose a device ability model including spatial information. In order to solve the problem of insufficient capacity of single devices, we then give a composite device ability model and relevant calculation formulae. Next, we introduce a novel device resource matching technique based on the proposed model. Compared with previous works, experimental results show that our technique achieves better recall and precision and meets WMSN application needs more effectively. Furthermore, our proposed approach greatly reduces the design complexity as well as the workload of application designers.
\end{abstract}

\section{Introduction}

Wireless multimedia sensor networks (WMSNs) [1] have drawn the attention of researchers in recent years, driven by a wealth of theoretical and practical challenges. This growing interest can be largely attributed to new applications enabled by large-scale networks of small devices, such as multimedia video surveillance systems, traffic avoidance and control systems, environment monitoring systems and so on [2]. Most WMSN applications require coordination and cooperation among large-scale multimedia devices in ubiquitous computing environments [3]. The matching between the large-scale device collaboration demand and device resources is the basis of the realization of WMSN applications. The resource ability matching technique [4], which is always a research hotspot in the field of collaboration technology [5-7], is realized by matching the requirement of virtual device capacity with the description of device resource ability.

In the WMSNs' environment, the multimedia device resource ability has the following characteristics [8]: (a) It

\footnotetext{
*Correspondence: jiafu_wan@ieee.org

${ }^{3}$ College of Information Engineering, Guangdong Jidian Polytechnic,

Guangzhou, China

Full list of author information is available at the end of the article
}

is related to the spatial extent [9], i.e., the device resource ability in a certain point of the space depends on both the absolute spatial position of this device resource and the relative spatial distance between this point and itself $[10,11]$. (b) It can be superimposed, i.e., superimposing multiple device resource ability in a certain point of the space may achieve better device ability in this point and meet greater requirement which single device could not satisfy [12-14].

Resource matching researches [15-20] currently focus on the web service matching, including syntax service matching [21] and semantic service matching [22]. The former [23] do exact keyword matching by registration information including the name and valid property values of the service in the service library, while the latter is based on semantic web technology. With the combination of ontology repository, matching service and authentication service, the latter can determine the matching degree between the request and service ability [24].

However, both the syntax service matching and the semantic matching are limited. The syntax service matching method [25] cannot accurately describe the desired multimedia device ability and measure the distance between the physical device ability and the desired device

\section{Springer}

(c) 2013 Zhang et al: licensee Springer. This is an Open Access article distributed under the terms of the Creative Commons Attribution License (http://creativecommons.org/licenses/by/2.0), which permits unrestricted use, distribution, and reproduction in any medium, provided the original work is properly cited. 
ability. Besides, the high user involvement [26] makes it hard to do service matching automatically in ubiquitous computing environment. The semantic service matching method, due to the huge type and number of devices in WMSNs, could not establish the ontology repository and make users understand easily. Furthermore, in the current study [27-29], since resource ability modeling always regards the resource access interface as a function and lacks the spatial location information of device, users build their own collaborative process only by understanding the details of all devices in the system [30], which is not suitable for WMSN applications in the WMSNs.

Given the above problems, this paper proposes a multimedia device resource matching method based on the device resource ability model. The remainder of the paper is organized as follows: Section 2 introduces the related work, Section 3 first defines a multimedia device ability model with spatial location information and its calculation formula which can calculate the device ability accurately and then gives a device resource matching method based on the above model to reduce the complexity in the design of large-scale device collaboration process of WMSN application, Section 4 gives the experimental results, and Section 5 concludes the paper.

\section{Related work}

Currently, there are various syntax service modeling techniques such as Web Service Description Language (WSDL), Resource Specification Language, Resource Description Framework (RDF), etc. Besides, there are also semantic service modeling techniques which include the RDFS (RDF Schema) [26], Web Ontology Language (OWL)/OWL-S [29], WSDL $[27,28]$, etc. Among them, the OWL-S has become a very important general resource description technique, which describes the attribute and function of the web resource from the syntax perspective and service perspective. Recently, researchers try to combine the OWL-S technique with the WSDL technique to achieve a new resource description resolution which has comprehensive superiority.

The syntax service matching method [31] focuses on the implementation details of the resource interface, which makes it easy to implement [32]. However, the recall and precision of this method is lower, and it cannot effectively support users doing service discovery based on functional semantic. The typical study is Universal Description, Discovery, and Integration (UDDI) [33-35]. UDDI uses WSDL to describe its web service and does exact keyword matching by the registration information in service library, mainly on ID, name, and valid property values of service.

The semantic service matching technique [36] focuses on the web service matching [37], including single service resource matching and service-oriented resource association matching [38]. The former research [39] used DAML-S for service modeling, which combines the users' needs with the properties of candidate service to achieve a single downlink (DL) expression. It judged the relationship between two collections of corresponding DL expressions by the DL inference engine and expanded the service matching algorithm. The latter research [40] solved the optimal matching problem among services using an exhaustive method. As the exponential growth of elapsed time, there will come a time-consuming problem when the parameters of service operation become larger [41], giving a service-oriented resource association matching mainly on interface parameter matching which does not filter the service matching according to the corresponding priority [42].

\section{Modeling and matching method 3.1 Definition}

In this section, we give the formal definition of device and device operation at first and then define the operation ability and performance attribute of device resource.

Definition 1. Terminal. In the large-scale device collaborative system, terminal is the smallest unit of the system control. Each terminal has finite states. Assume $t_{i}$ is a terminal, its state set is $\left\{t s_{1}, t s_{2}, \ldots, t s_{m}\right\}$, and one terminal can only be in one state at a time.

Definition 2. Device. In the large-scale device collaborative system, a device is composed by $n$ terminals and denoted as $d=\left\{t_{1}, t_{2}, \ldots, t_{n}\right\}$. The operation set supported by device $d$ is $\Sigma$, and the state set of device is $Q$.

Definition 3. Device state. The state of device $d=$ $\left\{t_{1}, t_{2}, \ldots, t_{n}\right\}$ is composed of $n$ terminal states. Assume that device $d$ has $k$ states, the state set $Q$ of device $d$ is $Q=\left\{s_{1}, s_{2}, \ldots, s_{k}\right\}$. Each device state $s$ is an ordered pair of $n$ terminal state, i.e., $s=\left\{t s_{t 1}, t s_{t 2}, \ldots, t s_{t n}\right\}$, where $t s_{t i}$ represents a state of terminal $t_{i}$.

According to the definition of the device state, we find that if a device contains $n$ terminals and each terminal has $m$ states, the number of device state is $m^{n}$.

Definition 4. Device operation. Device operation changes the device state by changing some terminal state of this device. Assume the collection $\Sigma$ of device operation in device $d=\left\{t_{1}, t_{2}, \ldots, t_{n}\right\}$ is $\Sigma=\left\{o p_{1}, o p_{2} \ldots, o p_{l}\right\}$, where $o p=\left\{<t_{i}, t s_{i}>, \ldots,<t_{j}, t s_{j}>\right\}, t_{i}, \ldots, t_{j} \in$ $\left\{t_{1}, t_{2}, \ldots, t_{n}\right\}$.

In the large-scale device collaborative system, according to the impact on the device state, the operating ability of device resource can be divided into three categories: monitor ability, basic control ability, and combination control 
ability. The first ability of device resource is monitor operation, whose collection is empty, and it is used for gaining the current state of the device. The second one is terminal control operation, whose collection contains only one element, and it can only set one terminal state each time. The last one is advanced control operation, whose collection contains multiple elements, and it can set several terminal states each time.

Definition 5. Composite device. In the large-scale device collaborative system, it is necessary that several devices work in parallel to achieve a synergistic effect, where all these devices are called a composite device.

Assume $d_{1}=\left\{t_{11}, t_{12}, \ldots, t_{1 n}\right\}, \ldots, d_{k}=\left\{t_{k 1}, t_{k 2}\right.$, $\left.\ldots, t_{k n}\right\}$ is a set of concurrent collaborative working devices. Then, its corresponding device operation set is $\Sigma_{1}, \ldots, \Sigma_{k}$, and the device state set is $Q_{1}, \ldots, Q_{k}$. The composite device com_d contains $\sum_{i=1}^{k} i n$ terminals, i.e., com_d $=\left\{d_{1}, \ldots, d_{k}\right\}$.

The operation set supported by composite device com_d is com_ $\Sigma=\left\{c o m \_o p_{1}, c o m \_o p_{2}, \ldots, c o m \_o p_{r}\right\}, c o m \_o p=$ $\bigcup_{i=1}^{k} o p_{i j_{i}}, o p_{i j_{i}} \in \Sigma_{i}, 1 \leq j_{i} \leq\left|\Sigma_{i}\right|$, and the number of composite device is $r=\prod_{i=1}^{k}\left|\Sigma_{i}\right|$.

The state set of composite device com_d is com_q $=\left\{\right.$ com_s $\left.s_{1}, c o m \_s_{2}, \ldots, c o m \_s\right\}, c o m \_s=\sum_{i=1}^{k}$ $s_{i j_{i}}, s_{i j_{i}} \in Q_{i}, 1 \leq j_{i} \leq\left|Q_{i}\right|$, and the number of composite device is $s=\prod_{i=1}^{k}\left|Q_{i}\right|$.

\subsection{The device resource ability model}

In the large-scale device collaborative system, the minimum ability calculation unit is the terminal ability model of the device. The ability of a device's operation is a union of the ability of terminal controlled by this device. The following is the description and calculation formula of these ability models.

\subsubsection{Terminal ability model}

Definition 6. Terminal ability. The terminal ability of a device refers to a set of function parameters in its spatial extent and state. Assuming that $t$ is a terminal and its state set is $\left\{t s_{1}, t s_{2}, \ldots, t s_{m}\right\}$, when $t s \in\left\{t s_{1}, t s_{2}, \ldots, t s_{m}\right\}$, the terminal ability is as follows:

$$
\begin{aligned}
t A(t, t s)= & f a\left(\sigma\left\{\left(x_{t 1}, y_{t 1}, z_{t 1}\right), \ldots,\left(x_{t m}, y_{t m}, z_{t m}\right)\right\},\right. \\
& \left.\left(a_{1}, a_{2}, \ldots, a_{n}\right)\right) t m \geq 1, n \geq 1
\end{aligned}
$$

- $\sigma\left\{\left(x_{t 1}, y_{t 1}, z_{t 1}\right), \ldots,\left(x_{t m}, y_{t m}, z_{t m}\right)\right\}$ represents the spatial extent of the terminal, and $t m=1$ indicates that the ability is on the point $\left(x_{t 1}, y_{t 1}, z_{t 1}\right)$.
- $a_{i}, 1 \leq i \leq n$ represents the $i$ th function parameter of the terminal.

- fa represents the map function between function parameters and spatial extent.

For example, denoting the state set in terminal of device $d=\left\{t_{1}, t_{2}, \ldots, t_{n}\right\}$ as $\{\mathrm{ON}, \mathrm{OFF}\}$, when the state of terminal $t$ is ON its ability is $t A(t, \mathrm{ON})=l \times r(l x)\left\{\left(x_{0}, y_{0}\right), \pi \times\right.$ $\left.\left((r+\Delta r)^{2}-r^{2}\right), 0 \leq r \leq r_{\max }\right\}$, and when the state is OFF, its terminal ability is $t A(t, \mathrm{OFF})=0(l x)\left\{\left(x_{0}, y_{0}\right), \pi \times\right.$ $\left.\left((r+\Delta r)^{2}-r^{2}\right), 0 \leq r \leq r_{\max }\right\}$. That is to say, in the twodimensional spatial extent $\left(x_{0}, y_{0}\right), \pi \times\left((r+\Delta r)^{2}-r^{2}\right)$, the ability of terminal $t$ is $l \times r$.

\subsubsection{Device ability model}

Definition 7. Device operation ability. The device operation ability refers to the aggregation of terminal ability in the spatial extent of device operation when this terminal is in its changing state. For device $d=\left\{t_{1}, t_{2}, \ldots, t_{n}\right\}$ and device operation $o p=\left\{<t_{i}, t s_{i}>, \ldots,<t_{j}, t s_{j}>\right\}$, $t_{i}, \ldots, t_{j} \in\left\{t_{1}, t_{2}, \ldots, t_{n}\right\}$, the device operation ability is as follows:

$$
\begin{gathered}
o p A(o p)=f a\left(\sigma\left\{\left(x_{o p 1}, y_{o p 1}, z_{o p 1}\right), \ldots,\left(x_{o p m}, y_{o p m}, z_{o p m}\right)\right\}\right. \\
\left.\left(a_{1}, a_{2}, \ldots, a_{n}\right)\right), o p m \geq 1, n \geq 1
\end{gathered}
$$

- $\sigma\left\{\left(x_{o p 1}, y_{o p 1}, z_{o p 1}\right), \ldots,\left(x_{o p m}, y_{o p m}, z_{o p m}\right)\right\}$ represents the spatial extent of the device operation.

- $a_{i}, 1 \leq i \leq n$ represents the $i$ th function parameter of the device operation.

- $f$ a represents the map function between function parameters and spatial extent.

Rule 1. Device operation ability calculation. Assume the function $\Omega$ is the cumulative calculation function of spatial extent, and $\Phi_{i}$ is the aggregation function of the $i$ th function parameter, $\Phi=\{\Sigma$, MAX, .. $\}$. The spatial extent and calculation rule of the function parameter of the device operation is as follows:

- The space extent of the device operation can be calculated by all the space extents of terminal controlled by this device, i.e.,

$$
\begin{array}{r}
\sigma\left\{\left(x_{o p 1}, y_{o p 1}, z_{o p 1}\right), \ldots,\left(x_{o p m}, y_{o p m}, z_{o p m}\right)\right\} \\
=\Omega\left(\sigma\left\{\left(x_{t i 1}, y_{t i 1}, z_{t i 1}\right), \ldots,\left(x_{t i m}, y_{t i m}, z_{t i m}\right)\right\}, \ldots,\right. \\
\left.\sigma\left\{\left(x_{t j 1}, y_{t j 1}, z_{t j 1}\right), \ldots,\left(x_{t j m}, y_{t j m}, z_{t j m}\right)\right\}\right) .
\end{array}
$$

- The function parameter of the device operation in spatial extent $\sigma\left\{\left(x_{1}, y_{1}, z_{1}\right), \ldots,\left(x_{m}, y_{m}, z_{m}\right)\right\}$ can be aggregated by all these function parameters of 
terminal controlled by this device in the same spatial extent, i.e.,

$$
\begin{array}{r}
\sigma\left\{\left(x_{1}, y_{1}, z_{1}\right), \ldots,\left(x_{m}, y_{m}, z_{m}\right)\right\}: a_{i} \\
=\Phi_{i}\left(\sigma\left\{\left(x_{1}, y_{1}, z_{1}\right), \ldots,\left(x_{m}, y_{m}, z_{m}\right)\right\}: a_{i i}, \ldots,\right. \\
\left.\sigma\left\{\left(x_{1}, y_{1}, z_{1}\right), \ldots,\left(x_{m}, y_{m}, z_{m}\right)\right\}: a_{j i}\right),
\end{array}
$$

where $a_{i i}, \ldots, a_{j i}$ is the corresponding function parameter of terminal control ability by the device operation.

For example, denoting the operation of device $d=$ $\left\{t_{1}, \ldots, t_{n}\right\}$ as $o p=\left\{<t_{1}, \mathrm{ON}>,<t_{2}, \mathrm{ON}>\right\}$, when the state of terminal $t_{1}$ is $\mathrm{ON}$, its terminal ability is $t A\left(t_{1}, \mathrm{ON}\right)=l_{1} \times r_{1}(l x)\left\{\left(x_{01}, y_{01}\right), \pi \times\left(\left(r_{1}+\Delta r\right)^{2}-\right.\right.$ $\left.\left.r_{1}^{2}\right), 0 \leq r_{1} \leq r_{\max }^{1}\right\}$, and when the state of terminal is OFF, its terminal ability is $t A\left(t_{2}, \mathrm{OFF}\right)=l_{2} \times$ $r_{2}(l x)\left\{\left(x_{02}, y_{02}\right), \pi \times\left(\left(r_{2}+\Delta r\right)^{2}-r_{2}^{2}\right), 0 \leq r_{2} \leq r_{\max }^{2}\right\}$. That is to say, in the two-dimensional spatial extent $\left(x_{0}, y_{0}\right), \pi \times\left((r+\Delta r)^{2}-r^{2}\right)$, the ability of terminal $t$ is $l \times r$.

Assume the operation space intersection for terminal $t_{1}$ and $t_{2}$ is as follows:

$$
\begin{array}{r}
\left\{\left(x_{01}, y_{01}\right), \pi \times\left(\left(r_{1}+\Delta r\right)^{2}-r_{1}{ }^{2}\right), 0 \leq r_{1} \leq r_{\max }^{1}\right\} \cap \\
\left\{\left(x_{02}, y_{02}\right), \pi \times\left(\left(r_{2}+\Delta r\right)^{2}-r_{2}{ }^{2}\right), 0 \leq r_{2} \leq r_{\max }^{2}\right\}=\sigma\left(r_{1}, r_{2}\right) .
\end{array}
$$

Then, the ability of device operation is as follows:

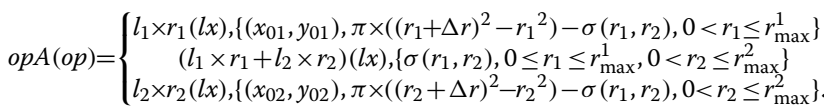

The spatial extent of device operation $O P$ is the union of the operation spatial extent for terminal $t_{1}$ and $t_{2}$, i.e., $\left\{\left(x_{01}, y_{01}\right), \pi \times\left(\left(r_{1}+\Delta r_{1}\right)^{2}-r_{1}^{2}\right)\right\} \cup\left\{\left(x_{02}, y_{02}\right), \pi \times\right.$ $\left.\left(\left(r_{2}+\Delta r_{2}\right)^{2}-r_{2}^{2}\right)\right\}$. The device operation ability is a piecewise function: in the intersection of two terminal's operation space $\sigma\left(r_{1}, r_{2}\right)$, the ability is $\left(l_{1} \times r_{1}+l_{2} \times r_{2}\right)$, i.e., the joint result of two terminals; in the terminal $t_{1}$ 's operation space, the ability is $l_{1} \times r_{1}$, i.e., the result of terminal $t_{1}$; and in the terminal $t_{2}$ 's operation space, the ability is $l_{2} \times r_{2}$, i.e., the result of terminal $t_{2}$.

Definition 8. Device ability. The device ability refers to all the device operation abilities in spatial extent. Assume the collection of device operation in device $d=$ $\left\{t_{1}, t_{2}, \ldots, t_{n}\right\}$ is $\Sigma=\left\{o p_{1}, o p_{2}, \ldots, o p_{l}\right\}$. The device ability is denoted as follows:

$$
\begin{gathered}
d A(d)=f a\left(\sigma\left\{\left(x_{d 1}, y_{d 1}, z_{d 1}\right), \ldots,\left(x_{d m}, y_{d m}, z_{d m}\right)\right\},\right. \\
\left.\left(a_{1}, a_{2}, \ldots, a_{n}\right)\right), d m \geq 1, n \geq 1
\end{gathered}
$$

- $\sigma\left\{\left(x_{d 1}, y_{d 1}, z_{d 1}\right), \ldots,\left(x_{d m}, y_{d m}, z_{d m}\right)\right\}$ denotes the spatial extent of the device.

- $a_{i}, 1 \leq i \leq n$ denotes the $i$ th function parameter of the device.

- $f$ a denotes the map function between function parameters and spatial extent.

Rule 2. Device ability calculation. Assume the function $\Omega$ is the cumulative calculation function of spatial extent, $\Phi_{i}$ is the aggregation function of the $i$ th function parameter, $\Phi=\{\Sigma, \operatorname{MAX}, \ldots\}$. The spatial extent and calculation rule of function parameter of a device is as follows:

- The space extent of a device can be calculated by all the space extents of the terminals controlled by this device, i.e.,

$$
\begin{aligned}
& \sigma\left\{\left(x_{d 1}, y_{d 1}, z_{d 1}\right), \ldots,\left(x_{d m}, y_{d m}, z_{d m}\right)\right\} \\
& =\Omega\left(\sigma\left\{\left(x_{t 11}, y_{t 11}, z_{t 11}\right), \ldots,\left(x_{t 1 m}, y_{t 1 m}, z_{t 1 m}\right)\right\}, \ldots,\right. \\
& \left.\sigma\left\{\left(x_{t n 1}, y_{t n 1}, z_{t n 1}\right), \ldots,\left(x_{t n m}, y_{t n m}, z_{t n m}\right)\right\}\right) .
\end{aligned}
$$

- The function parameter of a device in spatial extent $\sigma\left\{\left(x_{1}, y_{1}, z_{1}\right), \ldots,\left(x_{m}, y_{m}, z_{m}\right)\right\}$ can be aggregated by all the device operations in the same spatial extent. The minimum value of device function parameter $a_{i}$ in this spatial extent is:

$$
\begin{aligned}
& \sigma\left\{\left(x_{1}, y_{1}, z_{1}\right), \ldots,\left(x_{m}, y_{m}, z_{m}\right)\right\}: \theta_{\min }^{a i} \\
& =\operatorname{MIN}\left(\sigma\left\{\left(x_{1}, y_{1}, z_{1}\right), \ldots,\left(x_{m}, y_{m}, z_{m}\right)\right\}: a_{1 i},\right. \\
& \quad \sigma\left\{\left(x_{1}, y_{1}, z_{1}\right), \ldots,\left(x_{m}, y_{m}, z_{m}\right)\right\}: a_{2 i}, \ldots, \\
& \left.\quad \sigma\left\{\left(x_{1}, y_{1}, z_{1}\right), \ldots,\left(x_{m}, y_{m}, z_{m}\right)\right\}: a_{l i}\right),
\end{aligned}
$$

where $a_{1 i}, \ldots, a_{l i}$ is the corresponding function parameter of device ability.

The maximum value of device function parameter $a_{i}$ in this spatial extent is:

$$
\begin{aligned}
& \sigma\left\{\left(x_{1}, y_{1}, z_{1}\right), \ldots,\left(x_{m}, y_{m}, z_{m}\right)\right\}: \theta_{\max }^{a i} \\
& =\operatorname{MAX}\left(\sigma\left\{\left(x_{1}, y_{1}, z_{1}\right), \ldots,\left(x_{m}, y_{m}, z_{m}\right)\right\}: a_{1 i},\right. \\
& \\
& \sigma\left\{\left(x_{1}, y_{1}, z_{1}\right), \ldots,\left(x_{m}, y_{m}, z_{m}\right)\right\}: a_{2 i}, \ldots, \\
& \left.\sigma\left\{\left(x_{1}, y_{1}, z_{1}\right), \ldots,\left(x_{m}, y_{m}, z_{m}\right)\right\}: a_{l i}\right),
\end{aligned}
$$

where the interval of function parameter $a_{i}$ is:

$$
\begin{aligned}
& \sigma\left\{\left(x_{1}, y_{1}, z_{1}\right), \ldots,\left(x_{m}, y_{m}, z_{m}\right)\right\}: a_{i} \\
&= {\left[\sigma\left\{\left(x_{1}, y_{1}, z_{1}\right), \ldots,\left(x_{m}, y_{m}, z_{m}\right)\right\}: \theta_{\min }^{a i},\right.} \\
&\left.\sigma\left\{\left(x_{1}, y_{1}, z_{1}\right), \ldots,\left(x_{m}, y_{m}, z_{m}\right)\right\}: \theta_{\max }^{a i}\right] \\
&= {\left[\operatorname { M I N } \left(\sigma\left\{\left(x_{1}, y_{1}, z_{1}\right), \ldots,\left(x_{m}, y_{m}, z_{m}\right)\right\}: a_{1 i},\right.\right.} \\
& \sigma\left\{\left(x_{1}, y_{1}, z_{1}\right), \ldots,\left(x_{m}, y_{m}, z_{m}\right)\right\}: a_{2 i}, \ldots, \\
&\left.\sigma\left\{\left(x_{1}, y_{1}, z_{1}\right), \ldots,\left(x_{m}, y_{m}, z_{m}\right)\right\}: a_{l i}\right), \\
& \operatorname{MAX}\left(\sigma\left\{\left(x_{1}, y_{1}, z_{1}\right), \ldots,\left(x_{m}, y_{m}, z_{m}\right)\right\}: a_{1 i},\right. \\
& \sigma\left\{\left(x_{1}, y_{1}, z_{1}\right), \ldots,\left(x_{m}, y_{m}, z_{m}\right)\right\}: a_{2 i}, \ldots, \\
&\left.\left.\sigma\left\{\left(x_{1}, y_{1}, z_{1}\right), \ldots,\left(x_{m}, y_{m}, z_{m}\right)\right\}: a_{l i}\right)\right]
\end{aligned}
$$


For example, assume the operation set of device $d=$ $\left\{t_{1}, t_{2}, t_{3}\right\}$ is $\Sigma=\left\{o p_{1}, o p_{2}\right\}, o p_{1}=\left\{<t_{1}, \mathrm{ON}>,<\right.$ $\left.t_{2}, \mathrm{ON}>\right\}, o p_{2}=\left\{<t_{2}, \mathrm{OFF}>,<t_{3}, \mathrm{ON}>\right\}$. The abilities of device operation $o p_{1}$ and $o p_{2}$ are:

$o p A\left(o p_{1}\right)=\left\{\begin{array}{c}l_{1} \times r_{1}(l x),\left\{\left(x_{01}, y_{01}\right), \pi \times\left(\left(r_{1}+\Delta r\right)^{2}-r_{1}^{2}\right)-\sigma\left(r_{1}, r_{2}\right), 0<r_{1} \leq r_{\max }^{1}\right\} \\ \left(l_{1} \times r_{1}+l_{2} \times r_{2}\right)(l x),\left\{\sigma\left(r_{1}, r_{2}\right), 0 \leq r_{1} \leq r_{\max }^{1}, 0<r_{2} \leq r_{\max }^{2}\right\} \\ l_{2} \times r_{2}(l x),\left\{\left(x_{02}, y_{02}\right), \pi \times\left(\left(r_{2}+\Delta r\right)^{2}-r_{2}^{2}\right)-\sigma\left(r_{1}, r_{2}\right), 0<r_{2} \leq r_{\max }^{2}\right\}\end{array}\right.$

$$
\begin{aligned}
o p A\left(o p_{2}\right)= & l_{3} \times r_{3}(l x) \pi \\
& \times\left(\left(r_{3}+\Delta r\right)^{2}-r_{3}{ }^{2}\right), 0 \leq r_{3} \leq r_{\max }^{3}
\end{aligned}
$$

The intersection of operation spatial extent of terminals $t_{1}, t_{2}$, and $t_{3}$ is:

$$
\begin{aligned}
& \left\{\left(x_{01}, y_{01}\right), \pi \times\left(\left(r_{1}+\Delta r\right)^{2}-r_{1}^{2}\right), 0 \leq r_{1} \leq r_{\max }^{1}\right\} \cap \\
& \left\{\left(x_{02}, y_{02}\right), \pi \times\left(\left(r_{2}+\Delta r\right)^{2}-r_{2}^{2}\right), 0 \leq r_{2} \leq r_{\max }^{2}\right\} \cap \\
& \left\{\left(x_{03}, y_{03}\right), \pi \times\left(\left(r_{3}+\Delta r\right)^{2}-r_{3}^{2}\right), 0 \leq r_{3} \leq r_{\max }^{3}\right\}=\sigma\left(r_{1}, r_{2}, r_{3}\right) .
\end{aligned}
$$

Assume $l_{1} \leq l_{2} \leq l_{3}$, then the minimum device ability in operation spatial extent $\sigma\left(r_{1}, r_{2}, r_{3}\right)$ is:

$$
\theta_{\min }^{a}=\operatorname{MIN}\left(\left(l_{1}+l_{2}\right) \times r(l x), l_{3} \times r(l x)\right)=l_{3} \times r(l x) .
$$

The maximum device ability is:

$$
\theta_{\max }^{a}=\operatorname{MAX}\left(\left(l_{1}+l_{2}\right) \times r(l x), l_{3} \times r(l x)\right)=\left(l_{1}+l_{2}\right) \times r(l x) .
$$

The function parameter interval of the device ability is:

$$
a=\left[\theta_{\min }^{a}, \theta_{\max }^{a}\right]=\left[l_{3} \times r(l x),\left(l_{1}+l_{2}\right) \times r(l x)\right] .
$$

Similarly, when the operation spatial extent is $r_{\max }^{1}<$ $r \leq r_{\max }^{2}$ or $r_{\max }^{2}<r \leq r_{\max }^{3}$, the corresponding function parameter interval of the device ability is:

$$
\begin{aligned}
& a=\left[\theta_{\min }^{a}, \theta_{\max }^{a}\right]=\left[l_{2} \times r(l x), l_{3} \times r(l x)\right] . \\
& a=\left[\theta_{\min }^{a}, \theta_{\max }^{a}\right]=\left[l_{3} \times r(l x), l_{3} \times r(l x)\right] .
\end{aligned}
$$

The ability of the device $d=\left\{t_{1}, t_{2}, t_{3}\right\}$ is:

$$
d A(d)=\left\{\begin{array}{c}
{\left[l_{3} \times r(l x),\left(l_{1}+l_{2}\right) \times r(l x)\right] \pi \times\left((r+\Delta r)^{2}-r^{2}\right), 0 \leq r \leq r_{\max }^{1}} \\
{\left[\left(l_{2} \times r(l x), l_{3} \times r(l x)\right] \pi \times\left((r+\Delta r)^{2}-r^{2}\right), r_{\max }^{1}<r \leq r_{\max }^{2}\right.} \\
{\left[l_{3} \times r(l x),\left[l_{3} \times r(l x)\right] \pi \times\left((r+\Delta r)^{2}-r^{2}\right), r_{\max }^{2}<r \leq r_{\max }^{3}\right.}
\end{array}\right.
$$

\subsubsection{Composite device ability model}

Definition 9. Composite device operation ability. It refers to the aggregation of device operation ability when devices execute concurrently in the spatial extent of device operation. Assume comD $=\left\{d_{1}, \ldots, d_{k}\right\}$ is a composite device; the operation of this device is $\operatorname{comOp}=$ $\bigcup_{i=1}^{k} o p_{i}, o p_{i} \in \Sigma_{i}$, and the operation ability is as follows:

$\operatorname{comOpA}(\operatorname{comOp})=f a\left(\sigma\left\{\left(x_{c o m O p 1}, y_{c o m O p 1}, z_{c o m O p 1}\right), \ldots\right.\right.$, $\left(x_{\text {com Opm }}, y_{\text {comOpm }}, z_{\text {com }}\right.$ opm $\left.)\right\}$, $\left.\left(a_{1}, a_{2}, \ldots, a_{n}\right)\right), \mathrm{comOpm} \geq 1, n \geq 1$

- $\sigma\left\{\left(x_{c o m O p 1}, y_{c o m O p 1}, z_{c o m O p 1}\right), \ldots,\left(x_{c o m O p m}\right.\right.$, $\left.\left.y_{\text {com Opm }}, z_{\text {com Opm }}\right)\right\}$ represents the spatial extent of the device operation.

- $a_{i}, 1 \leq i \leq n$ represents the $i$ th function parameter of the device operation.

- $f$ a represents the map function between function parameters and spatial extent.

Rule 3. Composite device operation ability calculation. Assume the function $\Omega$ is the cumulative calculation function of spatial extent and is the aggregation function of the $i$ th function parameter, $\Phi=\{\Sigma$, MAX, .. Then, the spatial extent and calculation rule of function parameter of composite device operation is as follows:

- The space extent of composite device operation can be calculated by all the space extents of participated device operations, i.e.,

$$
\begin{gathered}
\sigma\left\{\left(x_{c o m O p 1}, y_{c o m O p 1}, z_{c o m O p 1}\right), \ldots,\left(x_{c o m O p m}, y_{c o m O p m}, z_{c o m O p m}\right)\right\} \\
=\Omega\left(\sigma\left\{\left(x_{o p 11}, y_{o p 11}, z_{o p 11}\right), \ldots,\left(x_{o p 1 m}, y_{o p 1 m}, z_{o p 1 m}\right)\right\}\right. \\
\left., \ldots \sigma\left\{\left(x_{o p k 1}, y_{o p k 1}, z_{o p k 1}\right), \ldots,\left(x_{o p k m}, y_{o p k m}, z_{o p k m}\right)\right\}\right)
\end{gathered}
$$

- The function parameter of composite device operation in spatial extent $\sigma\left\{\left(x_{1}, y_{1}, z_{1}\right), \ldots,\left(x_{m}, y_{m}\right.\right.$, $\left.\left.z_{m}\right)\right\}$ can be aggregated by all these function parameters of participated device operations in the same spatial extent, i.e.,

$$
\begin{aligned}
& \sigma\left\{\left(x_{1}, y_{1}, z_{1}\right), \ldots,\left(x_{m}, y_{m}, z_{m}\right)\right\}: a_{i} \\
& =\Phi_{i}\left(\sigma\left\{\left(x_{1}, y_{1}, z_{1}\right), \ldots,\left(x_{m}, y_{m}, z_{m}\right)\right\}: a_{1 i}, \ldots,\right. \\
& \left.\quad \sigma\left\{\left(x_{1}, y_{1}, z_{1}\right), \ldots,\left(x_{m}, y_{m}, z_{m}\right)\right\}: a_{k i}\right),
\end{aligned}
$$

where $a_{1 i}, \ldots, a_{l i}$ is the corresponding function parameter of the device operation ability. 
Definition 10. Composite device ability. The composite device ability refers to all the participated device abilities in spatial extent. Assume $\operatorname{com} D=\left\{d_{1}, \ldots, d_{k}\right\}$ is a composite device. The ability is denoted as follows:

$$
\begin{array}{r}
\operatorname{comDA}(\operatorname{comD})=f a\left(\sigma \left\{\left(x_{c o m D 1}, y_{c o m D 1}, z_{c o m D 1}\right), \ldots,\right.\right. \\
\left.\left(x_{c o m D m}, y_{c o m D m}, z_{c o m D m}\right)\right\} \\
\left.\left(a_{1}, a_{2}, \ldots, a_{n}\right)\right), c o m D m \geq 1, n \geq 1
\end{array}
$$

- $\sigma\left\{\left(x_{c d s 1}, y_{c d s 1}, z_{c d s 1}\right), \ldots,\left(x_{c d s m}, y_{c d s m}, z_{c d s m}\right)\right\}$ represents the spatial extent of composite device.

- $a_{i}, 1 \leq i \leq n$ represents the $i$ th function parameter of the device.

- $f$ a represents the map function between function parameters and spatial extent.

Rule 4. Composite device ability calculation. Assume the function $\Omega$ is the cumulative calculation function of spatial extent, $\Phi_{i}$ is the aggregation function of the $i$ th function parameter, and $\Phi=\{\Sigma, \operatorname{MAX}, \ldots\}$. The spatial extent and calculation rule of function parameter of composite device is as follows:

- The space extent of composite device can be calculated by all the space extents of participated devices, i.e.,

$$
\begin{aligned}
\sigma & \left\{\left(x_{c d s 1}, y_{c d s 1}, z_{c d s 1}\right), \ldots,\left(x_{c d s m}, y_{c d s m}, z_{c d s m}\right)\right\} \\
= & \Omega\left(\sigma\left\{\left(x_{d 11}, y_{d 11}, z_{d 11}\right), \ldots,\left(x_{d 1 m}, y_{d 1 m}, z_{d 1 m}\right)\right\}, \ldots,\right. \\
& \left.\sigma\left\{\left(x_{d k 1}, y_{d k 1}, z_{d k 1}\right), \ldots,\left(x_{d k m}, y_{d k m}, z_{d k m}\right)\right\}\right)
\end{aligned}
$$

- The function parameter of composite device in spatial extent $\sigma\left\{\left(x_{1}, y_{1}, z_{1}\right), \ldots,\left(x_{m}, y_{m}, z_{m}\right)\right\}$ can be aggregated by all these function parameters of participated devices in the same spatial extent, i.e., the minimum value of the device function parameter in this spatial extent is:

$$
\begin{aligned}
\sigma & \left\{\left(x_{1}, y_{1}, z_{1}\right), \ldots,\left(x_{m}, y_{m}, z_{m}\right)\right\}: \theta_{\min }^{a i} \\
= & \operatorname{MIN}\left(\sigma\left\{\left(x_{1}, y_{1}, z_{1}\right), \ldots,\left(x_{m}, y_{m}, z_{m}\right)\right\}: \theta_{\min }^{a 1 i},\right. \\
& \sigma\left\{\left(x_{1}, y_{1}, z_{1}\right), \ldots,\left(x_{m}, y_{m}, z_{m}\right)\right\}: \theta_{\min }^{a 2 i}, \ldots, \\
& \left.\sigma\left\{\left(x_{1}, y_{1}, z_{1}\right), \ldots,\left(x_{m}, y_{m}, z_{m}\right)\right\}: \theta_{\min }^{a k i}\right),
\end{aligned}
$$

where $a_{1 i}, \ldots, a_{l i}$ is the corresponding function parameter of composite device ability.
The maximum value of device function parameter $a_{i}$ in this spatial extent is:

$$
\begin{aligned}
\sigma & \left\{\left(x_{1}, y_{1}, z_{1}\right), \ldots,\left(x_{m}, y_{m}, z_{m}\right)\right\}: \theta_{\max }^{a i} \\
= & \operatorname{MAX}\left(\sigma\left\{\left(x_{1}, y_{1}, z_{1}\right), \ldots,\left(x_{m}, y_{m}, z_{m}\right)\right\}: \theta_{\max }^{a 1 i},\right. \\
& \sigma\left\{\left(x_{1}, y_{1}, z_{1}\right), \ldots,\left(x_{m}, y_{m}, z_{m}\right)\right\}: \theta_{\max }^{a 2 i}, \ldots, \\
& \left.\sigma\left\{\left(x_{1}, y_{1}, z_{1}\right), \ldots,\left(x_{m}, y_{m}, z_{m}\right)\right\}: \theta_{\max }^{a k i}\right),
\end{aligned}
$$

where the interval of the function parameter $a_{i}$ is:

$$
\begin{aligned}
& \sigma\left\{\left(x_{1}, y_{1}, z_{1}\right), \ldots,\left(x_{m}, y_{m}, z_{m}\right)\right\}: a_{i} \\
& =\left[\sigma\left\{\left(x_{1}, y_{1}, z_{1}\right), \ldots,\left(x_{m}, y_{m}, z_{m}\right)\right\}: \theta_{\text {min }}^{a i},\right. \\
& \left.\sigma\left\{\left(x_{1}, y_{1}, z_{1}\right), \ldots,\left(x_{m}, y_{m}, z_{m}\right)\right\}: \theta_{\max }^{a i}\right] \\
& =\left[\operatorname { M I N } \left(\sigma\left\{\left(x_{1}, y_{1}, z_{1}\right), \ldots,\left(x_{m}, y_{m}, z_{m}\right)\right\}: \theta_{\mathrm{min}}^{a 1 i}\right.\right. \text {, } \\
& \sigma\left\{\left(x_{1}, y_{1}, z_{1}\right), \ldots,\left(x_{m}, y_{m}, z_{m}\right)\right\}: \theta_{\text {min }}^{a 2 i}, \ldots, \\
& \left.\sigma\left\{\left(x_{1}, y_{1}, z_{1}\right), \ldots,\left(x_{m}, y_{m}, z_{m}\right)\right\}: \theta_{\min }^{a k i}\right), \\
& \operatorname{MAX}\left(\sigma\left\{\left(x_{1}, y_{1}, z_{1}\right), \ldots,\left(x_{m}, y_{m}, z_{m}\right)\right\}: \theta_{\max }^{a 1 i}\right. \text {, } \\
& \sigma\left\{\left(x_{1}, y_{1}, z_{1}\right), \ldots,\left(x_{m}, y_{m}, z_{m}\right)\right\}: \theta_{\max }^{a 2 i}, \ldots, \\
& \left.\left.\sigma\left\{\left(x_{1}, y_{1}, z_{1}\right), \ldots,\left(x_{m}, y_{m}, z_{m}\right)\right\}: \theta_{\max }^{a k i}\right)\right] \text {. }
\end{aligned}
$$

\subsection{Device resource matching method based on ability model}

Resource matching is a process $[43,44]$ which selects a resource candidate set among the device resource sets based on a given user demand. Every device resource contained in the resource candidate set meets the demand. We first give the description of user device ability requirements as follows and then propose the device ability matching method in a large-scale device collaboration system.

\subsubsection{Description of user demand}

The user demand for device resource ability $[45,46]$ involved in a process is a sum of all ability demands for virtual device resource. It is denoted as $R=\left\{r_{1}, \ldots, r_{m}\right\}, m \geq$ 1 , where $r$ presents a description of a user's demand, i.e., the ability demand of virtual device resource. $r$ can be presented in a tuple: $r=(d s s, r s)$.

- $d s s=d s$ represents the virtual device resource involved in the description of user demand.

- $r s$ represents the user demand for the virtual device resource ability in the description: $r s=d A\left(d s_{1}\right)$.

\subsubsection{Device ability matching method}

Rule 5. Device ability matching. Assume $R=\left\{r_{1}, \ldots, r_{m}\right\}$, $m \geq 1$ is the description of user demand in device collaboration process. The demand of device resource ability $r=(d s s, r s), r s=d A(d s)$ is as follows: 


$$
\begin{array}{r}
d A(d s)=f a\left(\sigma\left\{\left(x_{d s 1}, y_{d s 1}, z_{d s 1}\right), \ldots,\left(x_{d s m}, y_{d s m}, z_{d s m}\right)\right\},\right. \\
\left.\left(a_{1 s}, a_{2 s}, \ldots, a_{n s}\right)\right), \quad d s m \geq 1, n s \geq 1,
\end{array}
$$

and the ability of device $d$ is:

$$
\begin{array}{r}
d A(d)=f a\left(\sigma\left\{\left(x_{d 1}, y_{d 1}, z_{d 1}\right), \ldots,\left(x_{d m}, y_{d m}, z_{d m}\right)\right\},\right. \\
\left.\left(a_{1}, a_{2}, \ldots, a_{n}\right)\right), \quad d m \geq 1, n \geq 1 .
\end{array}
$$

If device $d$ meets the following three conditions at the same time, then we believe that this device matches the device resource ability in users' demand:

$$
\begin{gathered}
\sigma\left\{\left(x_{d s 1}, y_{d s 1}, z_{d s 1}\right), \ldots,\left(x_{d s m}, y_{d s m}, z_{d s m}\right)\right. \\
\preceq \sigma\left\{\left(x_{d 1}, y_{d 1}, z_{d 1}\right), \ldots,\left(x_{d m}, y_{d m}, z_{d m}\right)\right. \\
\left(a_{1 s}, a_{2 s}, \ldots, a_{n s}\right) \subseteq\left(a_{1}, a_{2}, \ldots, a_{n}\right) \\
\text { - } \quad \forall \sigma\left\{\left(x_{1}, y_{1}, z_{1}\right), \ldots,\left(x_{m}, y_{m}, z_{m}\right)\right\} \\
\preceq \sigma\left\{\left(x_{d s 1}, y_{d s 1}, z_{d s 1}\right), \ldots,\left(x_{d s m}, y_{d s m}, z_{d s m}\right),\right. \\
\quad \forall a_{i s} \in\left(a_{1 s}, a_{2 s}, \ldots, a_{n s}\right) \\
\quad \sigma\left\{\left(x_{1}, y_{1}, z_{1}\right), \ldots,\left(x_{m}, y_{m}, z_{m}\right)\right\}: \\
\quad a_{i s} \cap \sigma\left\{\left(x_{1}, y_{1}, z_{1}\right), \ldots,\left(x_{m}, y_{m}, z_{m}\right)\right\}: a_{i} \neq \varphi
\end{gathered}
$$

where $a_{i s}$ and $a_{i}$ are the same function parameter

$$
a_{i} \in\left(a_{1}, a_{2}, \ldots, a_{n}\right) \text {. }
$$

\subsubsection{Composite device ability matching method}

Definition 11. Matching distance of device ability. It refers to the size of operation spatial extent and function parameter matching between two devices. Assume the abilities of devices $d_{1}$ and $d_{2}$ are as follows:

$$
\begin{array}{r}
d A\left(d_{1}\right)=f a\left(\sigma\left\{\left(x_{d 11}, y_{d 11}, z_{d 11}\right), \ldots,\left(x_{d 1 m}, y_{d 1 m}, z_{d 1 m}\right)\right\}\right. \\
\left.\left(a_{11}, a_{12}, \ldots, a_{1 n}\right)\right), d 1 m \geq 1,1 n \geq 1
\end{array}
$$

$$
d A\left(d_{2}\right)=f a\left(\sigma\left\{\left(x_{d 21}, y_{d 21}, z_{d 21}\right), \ldots,\left(x_{d 2 m}, y_{d 2 m}, z_{d 2 m}\right)\right\}\right.
$$$$
\left.\left(a_{21}, a_{22}, \ldots, a_{2 n}\right)\right), d 2 m \geq 1,2 n \geq 1 \text {. }
$$

The matching distance of device ability is calculated as follows:

$$
F\left(d A\left(d_{1}\right), d A\left(d_{2}\right)\right)=\sqrt{\left(\sigma_{1}-\sigma_{2}\right)^{2}+\sum_{i=1}^{n}\left(a_{1 i}-a_{2 i}\right)^{2}}
$$

Table 1 Configuration of ability matching experiment

\begin{tabular}{lll}
\hline Name & Hardware & Software \\
\hline Device collaborative & CPU Intel Core Duo 2.6 GHz & Windows XP \\
task requests simulator & Memory 2.00 GB & JDK1.5 \\
& Network 10/100M Ethernet & \\
Large-scale device & CPU Intel Core 2.6 GHz & Suse Linux \\
collaboration system & Memory 4.00 GB & JDK1.5 \\
& Network 10/100M Ethernet & \\
Device simulator server & CPU Intel Core 2.6 GHz & Suse Linux \\
& Memory 2.00 GB & JDK1.5 \\
& Network 10/100M Ethernet & Tomcat 5.5.14 \\
\hline
\end{tabular}

$$
\begin{aligned}
\sigma_{1} & =\sigma\left\{\left(x_{11}, y_{11}, z_{11}\right), \ldots,\left(x_{1 m}, y_{1 m}, z_{1 m}\right)\right\} \\
\sigma_{2} & =\sigma\left\{\left(x_{21}, y_{21}, z_{21}\right), \ldots,\left(x_{2 m}, y_{2 m}, z_{2 m}\right)\right\}
\end{aligned}
$$

- $a_{1 i}$ and $a_{2 i}$ are the same function parameters, $a_{1 i} \in\left(a_{11}, a_{12}, \ldots, a_{1 n}\right), a_{2 i} \in\left(a_{21}, a_{22}, \ldots, a_{2 n}\right)$.

Now, we give our composite ability matching algorithm based on the above matching distance. Assume $D_{s}=$ $\left\{d_{1}, \ldots, d_{l}\right\}, l \geq 0$ is the device satisfied by users, and $D_{a l}=\left\{d_{1}, \ldots, d_{k}\right\}, k \geq 1$ is the device in the large-scale collaborative system. The description of algorithm is as follows:

1. The first input is the device resource ability $r=(d s s, r s), r s=d A(d s)$ of users' demand $R=\left\{r_{1}, \ldots, r_{m}\right\}, m \geq 1$ in the large-scale collaborative system, i.e.,

$$
\begin{array}{r}
d A(d s)=f a\left(\sigma\left\{\left(x_{d s 1}, y_{d s 1}, z_{d s 1}\right), \ldots,\left(x_{d s m}, y_{d s m}, z_{d s m}\right)\right\}\right. \\
\left.\left(a_{1 s}, a_{2 s}, \ldots, a_{n s}\right)\right), d s m \geq 1, n s \geq 1 .
\end{array}
$$

The second input is the device set $D=D_{a s}-D_{s}=$ $\left\{d_{1}, \ldots, d_{n}\right\}, n \geq 1$ except that meets the demand, i.e.,

$$
\begin{array}{r}
d A\left(d_{i}\right)=f a\left(\sigma\left\{\left(x_{d i 1}, y_{d i 1}, z_{d i 1}\right), \ldots,\left(x_{\operatorname{dim}}, y_{\operatorname{dim}}, z_{\operatorname{dim}}\right)\right\}\right. \\
\left.\left(a_{1 i}, a_{2 i}, \ldots, a_{n i}\right)\right), \operatorname{dim} \geq 1, n i \geq 1 .
\end{array}
$$

Table 2 Parameters of ability matching experiment

\begin{tabular}{ll}
\hline Name & Description \\
\hline Depth & $\begin{array}{l}\text { Device ability matching depth, i.e., the maximum } \\
\text { number of matching candidate found by virtual device } \\
\text { TN }\end{array}$ \\
& $\begin{array}{l}\text { The number of devices with different abilities in } \\
\text { AN }\end{array}$ \\
& The number of ability parameters in large-scale \\
&
\end{tabular}




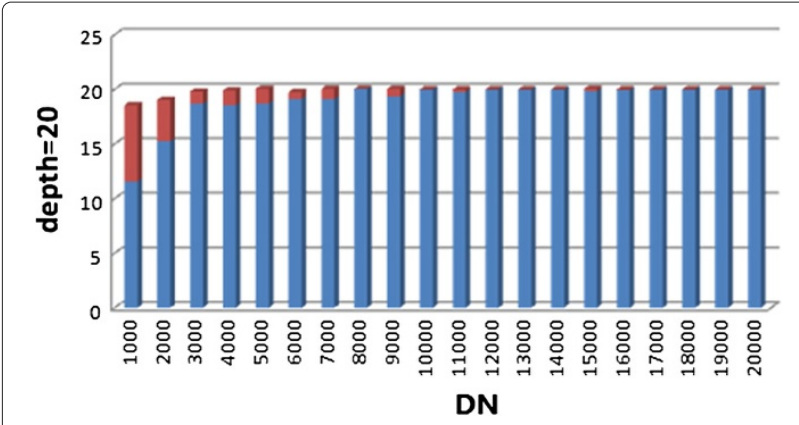

Figure 1 Distribution of candidate device resource (depth $=20$ ).

2. Set the matching depth of composite device be $k$.

3. Calculate the device ability matching distance $F\left(d A\left(d_{i}\right), d A(d s)\right), d_{i} \in D$ in device set $D=\left\{d_{1}, \ldots, d_{n}\right\}, n \geq 1$.

4. Add the device $d_{i}$ with the minimum matching distance to the candidate composite device $\operatorname{com} D_{k}$ where $D=D-d_{i}, d A(d s)=d A(d s)-d A\left(d_{i}\right)$.

5. Repeat steps 3 and 4 until $d A(d s)=0$; now $\operatorname{comD}_{k}$ is a candidate composite device.

6. If all the devices are traversed and $d A(d s) \neq 0$, the algorithm terminates; otherwise, repeat steps 3,4 , and 5 to find the candidate composite devices $c o m D_{k}$ which meet the matching depth $k$.

The following is the detail algorithm (Algorithm 1):

\section{Experiments}

\subsection{Configuration}

The experiments are conducted in three desktop computers: the first one simulates the requests of device collaborative tasks, the second one deploys a large-scale device collaboration system which uses our proposed matching method to assign the device resource with collaborative tasks, and the last one deploys a device simulator which can produce a lot of device resources with different abilities. Tables 1 and 2 show the configuration and parameters in our experiments, respectively.

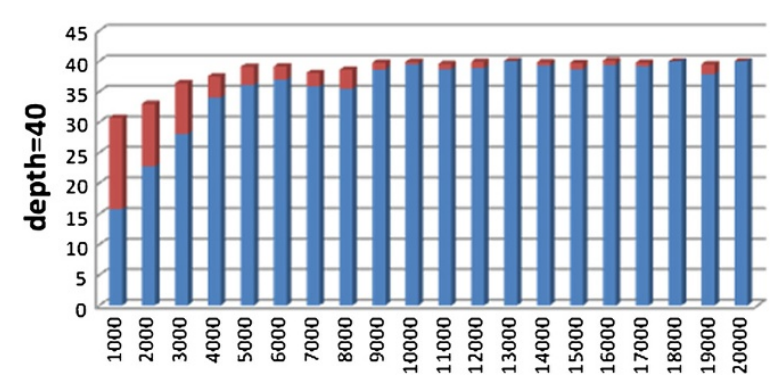

Figure 2 Distribution of candidate device resource (depth $=40$ ).

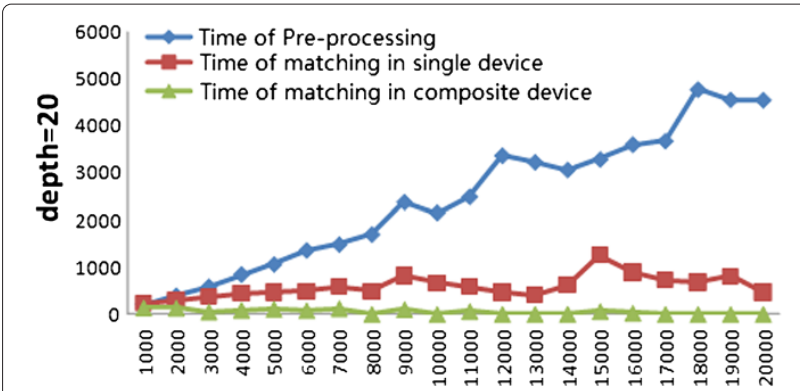

Figure 3 Time of device ability matching (depth $=20$ ).

\subsection{Effect of matching method}

This part measures the relationship between the number of candidate device resource in virtual device and the total number of device resource in a system. Assume the matching depth of device ability depth $=40$, the parameter number of device ability $\mathrm{AN}=2$, and the number of device in large-scale collaborative system is $1,000,2,000, \ldots, 20,000$, respectively. In order to reduce the random error, each test performs 50 times.

Figures 1 and 2 show the result: When the total number of devices $\mathrm{DN}=1,000$, our matching method can ensure the percentage of candidate device resource to be more than 75; and with the growth of the total number, this percentage becomes nearly 100 , which indicates that our matching method can meet the effect demand of large-scale device collaboration system.

\subsection{Performance of matching method}

This part tests the performance of our matching method. Assume the matching depth of device ability depth $=40$, the parameter number of device ability $\mathrm{AN}=2$, and the number of device in large-scale collaborative system be $1,000,2,000, \ldots, 20,000$, respectively. In order to reduce the random error, each test is performed 50 times.

Figures 3 and 4 show the result due to the preprocessing operation for device matching; the growth of the total number of device in the system only affects the increase in time of pre-processing, while it affects matching time a little. Besides, when $\mathrm{DN}=20,000$, the total

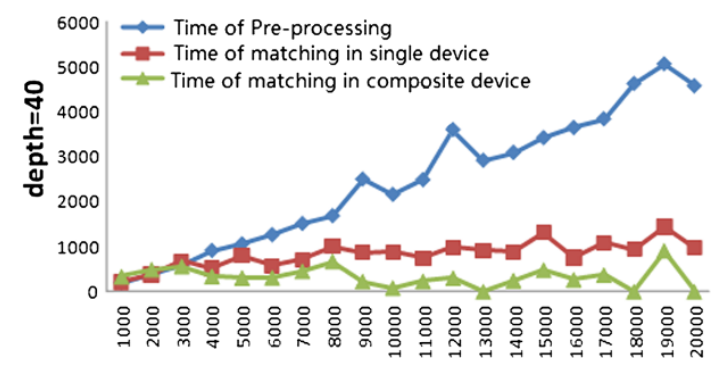

Figure 4 Time of device ability matching (depth $=40$ ). 


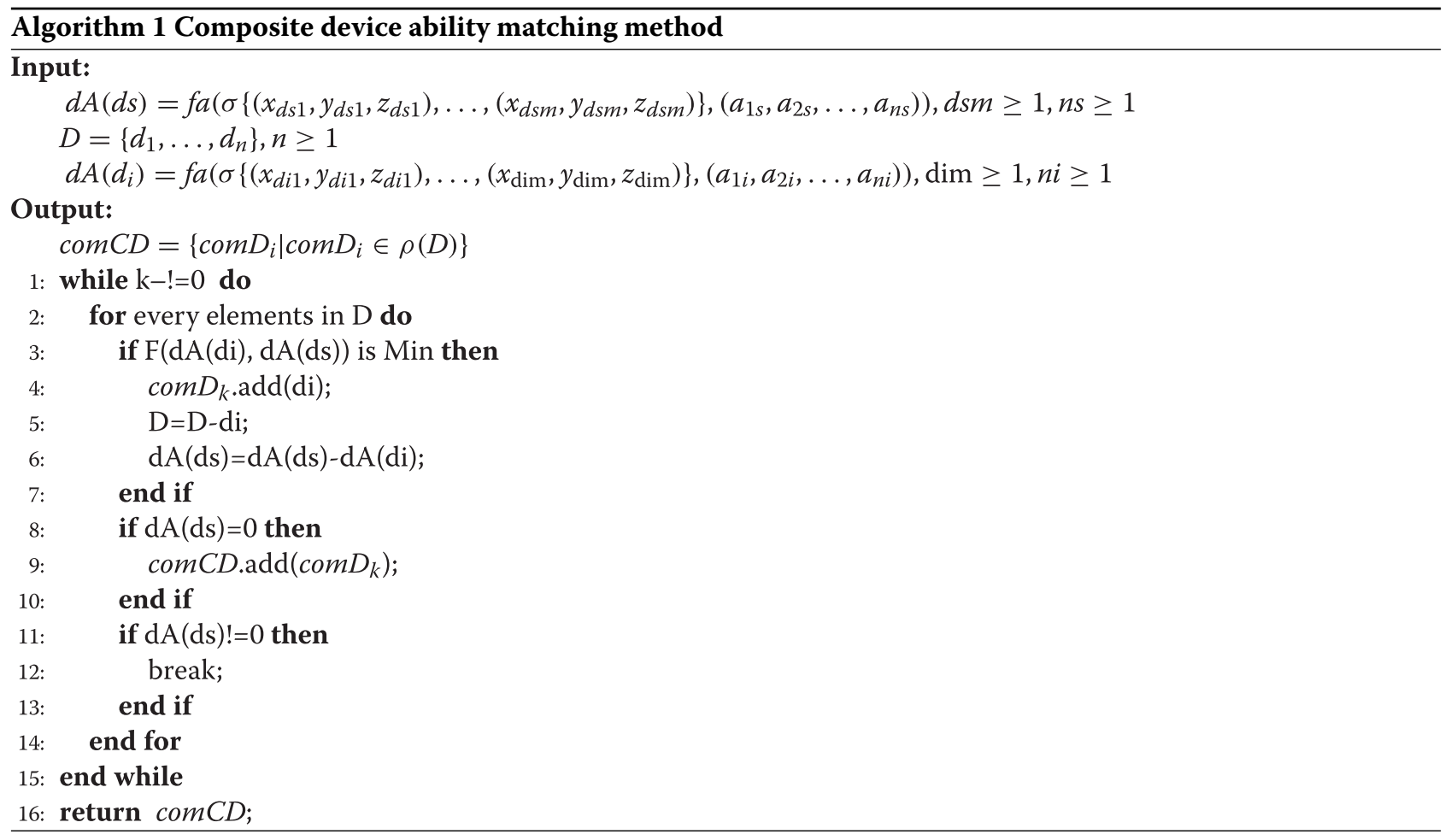

Table 3 The number of matching resources in the case of different devices

\begin{tabular}{|c|c|c|c|c|c|c|}
\hline \multirow{2}{*}{$\begin{array}{l}\text { Device } \\
\text { number }\end{array}$} & \multicolumn{3}{|c|}{ Depth $=20$} & \multicolumn{3}{|c|}{ Depth $=40$} \\
\hline & Total number & $d$ Number & comD Number & Total number & $d$ number & $\begin{array}{l}\text { comD } \\
\text { Number }\end{array}$ \\
\hline 1,000 & 18.55 & 11.55 & 7 & 30.7 & 15.8 & 14.9 \\
\hline 2,000 & 19.05 & 15.25 & 3.8 & 33 & 22.8 & 10.2 \\
\hline 5,000 & 20 & 18.7 & 1.3 & 39.1 & 36.1 & 3 \\
\hline 10,000 & 20 & 20 & 0 & 39.9 & 39.5 & 0.4 \\
\hline 15,000 & 20 & 19.8 & 0.2 & 39.7 & 38.7 & 1 \\
\hline 20,000 & 20 & 20 & 0 & 40 & 40 & 0 \\
\hline
\end{tabular}

Table 4 The time of matching resources in the case of different devices

\begin{tabular}{|c|c|c|c|c|c|c|}
\hline \multirow{2}{*}{$\begin{array}{l}\text { Device } \\
\text { number }\end{array}$} & \multicolumn{3}{|c|}{ Depth $=20$} & \multicolumn{3}{|c|}{ Depth $=40$} \\
\hline & Filter time & $d$ Time & comD Time & Filter time & $d$ Time & comD Time \\
\hline 1,000 & 195.8 & 223.0 & 134.15 & 184.1 & 210.6 & 327.6 \\
\hline 2,000 & 380.7 & 296.3 & 132.65 & 365.2 & 382.15 & 487.4 \\
\hline 5,000 & $1,048.2$ & 461.8 & 112.35 & $1,049.1$ & 794.05 & 302.7 \\
\hline 10,000 & $2,144.1$ & 659.8 & 0 & $2,148.9$ & 882.2 & 79.55 \\
\hline 15,000 & $3,279.2$ & 1,248 & 59.25 & $3,411.8$ & $1,304.85$ & 477.35 \\
\hline 20,000 & $4,544.2$ & 458.7 & 0 & $4,566.2$ & 964.05 & 0 \\
\hline
\end{tabular}




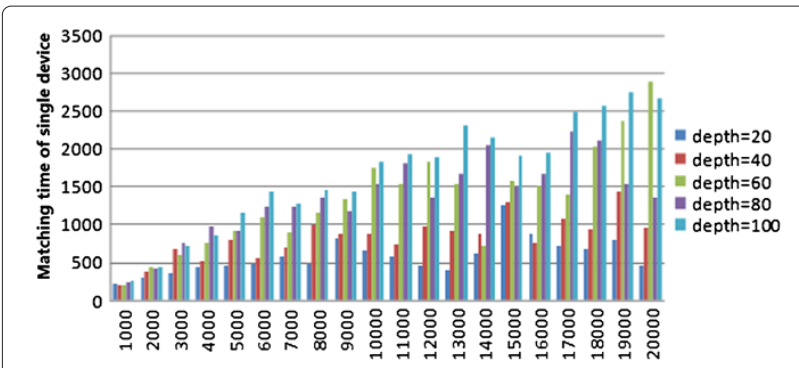

Figure 5 The relationship between single device matching time and DN.

time of device ability matching is less than $6 \mathrm{~s}$, which indicates that our matching method can meet the performance demand of large-scale device collaboration system. The details are in Tables 3 and 4.

\subsection{Matching method between single and composite device}

This part measures the relationship between matching time and number of device resource in the case of different matching depths. Assume the matching depth of device ability depth $=20,40,60,80$, and 100 , respectively, the parameter number of device ability $\mathrm{AN}=$ 2 , and the number of device in large-scale collaborative system be $1,000,2,000, \ldots, 20,000$, respectively. In order to reduce the random error, each test is performed 50 times.

Figures 5 and 6 show the result when depth < 40; the matching time of both single and composite device increase slowly with the growth of total device number DN. The reason is that in device ability matching process, we should use as less as possible devices to meet the demand of virtual device in order to reduce the conflict of device operations. Thus, when the matching depth is small, single device will meet the requirement.

However, the matching time of composite device grows rapidly with the growth of total device number DN, which indicates that considering both the less conflict of device

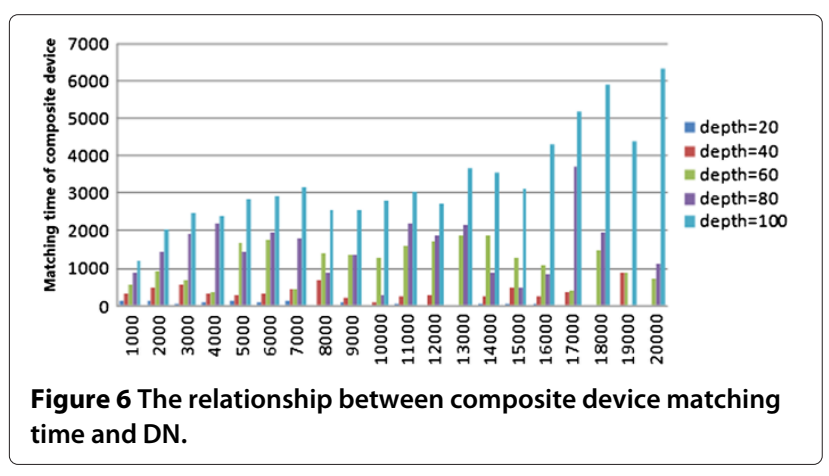

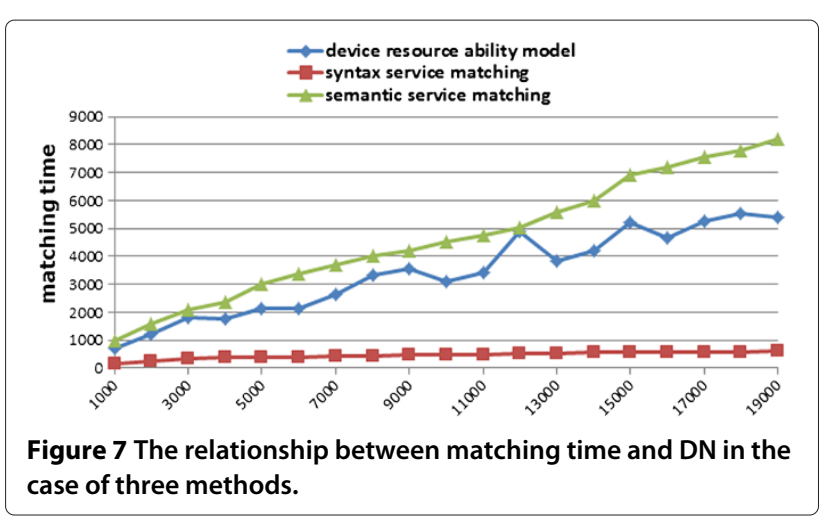

operation and higher matching efficiency of device ability, we should select as less as possible devices to meet the demand of virtual device.

\subsection{Comparisons with traditional methods}

At present, resources matching research mainly conclude syntax service matching and semantic service matching. In order to compare the efficiency of our proposed device resource matching method based on the device resource ability model with the two traditional resource matching methods, we designed a set of comparative experiments, testing in the case of the same user requirements how much time is cost by each of the resource matching technique and how many devices are matched up by each of the technique.

Assume the matching depth of device ability depth $=$ 40 , the number of device in large-scale collaborative system is $1,000,2,000, \ldots, 20,000$, respectively. In order to reduce the random error, each test is performed 50 times.

In Figures 7 and 8, horizontal axes show the total number of devices DN in large-scale device collaboration system, and the vertical axes show the cost time used for matching and the number of the candidate devices matched, respectively. It can be seen that syntax service

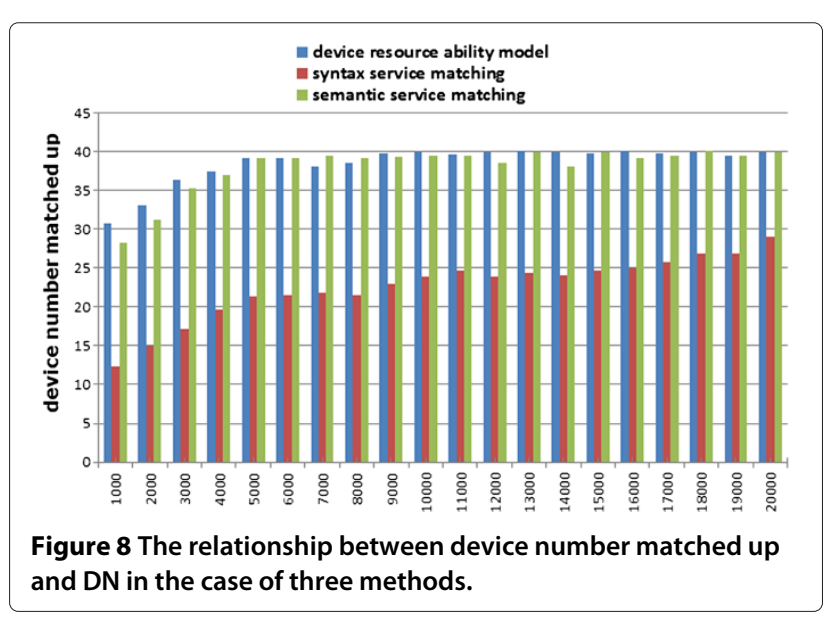


Table 5 Part of the experimental data

\begin{tabular}{|c|c|c|c|c|c|c|}
\hline \multirow[b]{2}{*}{ Device number } & \multicolumn{3}{|c|}{ Cost time } & \multicolumn{3}{|c|}{ Number of matched resources } \\
\hline & $\begin{array}{l}\text { Device } \\
\text { ability } \\
\text { model }\end{array}$ & $\begin{array}{c}\text { Syntax } \\
\text { service } \\
\text { matching }\end{array}$ & $\begin{array}{c}\text { Semantic } \\
\text { service } \\
\text { matching }\end{array}$ & $\begin{array}{l}\text { Device } \\
\text { ability } \\
\text { model }\end{array}$ & $\begin{array}{c}\text { Syntax } \\
\text { service } \\
\text { matching }\end{array}$ & $\begin{array}{c}\text { Semantic } \\
\text { service } \\
\text { matching }\end{array}$ \\
\hline 1,000 & 722.3 & 163.4 & 986.05 & 30.7 & 12.4 & 28.3 \\
\hline 2,000 & $1,234.75$ & 240.33 & $1,564.35$ & 33 & 15 & 31.2 \\
\hline 5,000 & $2,145.85$ & 398.15 & 2,988 & 39.1 & 21.3 & 39.2 \\
\hline 10,000 & $3,110.65$ & 478.25 & $4,534.38$ & 39.9 & 23.9 & 39.5 \\
\hline 15,000 & $5,194.05$ & 553.25 & $6,933.55$ & 39.7 & 24.6 & 40 \\
\hline 20,000 & $5,530.25$ & 602.3 & $8,022.25$ & 40 & 29 & 40 \\
\hline
\end{tabular}

matching method costs the least amount of time, but the matching result is not so good as the result of our proposed method. The number of the candidate devices is far less than the number of matched devices in the case of the device resource ability model matching method and semantic matching method. The effect of the semantic service matching method is almost the same with our proposed device resource matching method based on the device resource ability model, but the semantic service matching method costs much more time than that of our proposed method cost. In order to analyze the experimental results quantitatively, we give part of the experimental data in our experiments (Table 5).

\section{Conclusions}

WMSN applications usually involve a large number of devices and complex spatial information configurations. To address this challenge, in this article, we propose a multimedia device ability model, which incorporates spatial information management into the modeling phase. Based on this model, we further derive a multimedia device resource matching technique for ubiquitous computing environments. By adopting this technology, automatic execution of the collaboration process is done efficiently. Experimental results show that our proposed technique achieves better recall and precision. Compared with previous works, our approach not only has better performance but also meets WMSN application needs much better. The multimedia device ability matching method can greatly reduce the design complexity and workload of application designers.

\section{Competing interests}

The authors declare that they have no competing interests.

\section{Acknowledgements}

The work was supported by the National Natural Science Foundation of China (nos. 61100066, 61133005, 61262013), Special Fund Research in the Public Interest (no. 201008002), the National Science Foundation of Guangdong Province, China (no. S2011010001155), and the High-level Talent Project for Universities, Guangdong Province, China (431, YueCailiao 2011).

\section{Author details}

${ }^{1}$ State Key Laboratory of Software Development Environment, Beihang University, Beijing, China. ${ }^{2}$ Lab of Parallel Software and Computational Science, Institute of Software Chinese Academy of Sciences, Beijing, China. ${ }^{3}$ College of Information Engineering, Guangdong Jidian Polytechnic, Guangzhou, China.

Received: 1 January 2013 Accepted: 15 May 2013

Published: 4 July 2013

\section{References}

1. M Chen, CF Lai, HG Wang, Mobile multimedia sensor networks: architecture and routing. EURASIP J Wireless Commun. Netw. 2011, 1-9 (2011)

2. J Campbell, PB Gibbons, S Nath, P Pillai, S Seshan, R Sukthankar, in Proceedings of the 13th Annual ACM International Conference on Multimedia. IrisNet: an internet-scale architecture for multimedia sensors (ACM, New York, 2005), pp. 81-88

3. M Chen, V Leung, SW Mao, Y Yuan, Directional geographical routing for real-time video communications in wireless sensor networks. Comput. Commun. 30(17), 3368-3383 (2007)

4. CH Chen-Ritzo, C Harrison, J Paraszczak, F Parr, Instrumenting the planet. IBM J. Res. Dev. 53(3), 1 (2009)

5. P Deng, JW Zhang, XH Rong, F Chen, Modeling the large-scale device control system based on PI-calculus. Adv. Sci. Lett. 4(6-7), 6-7 (2011)

6. $\quad$ P Deng, $F$ Chen, $X H$ Rong, $P$ Jiang, $W$ Jin, A meta communication protocol in support lighting device unified access of olympic center. ITCS. 2, 48-52 (2009)

7. DJ Sobajic, YH Pao, Artificial neural-net based dynamic security assessment for electric power systems. Power Sys. IEEE Trans. 4, 220-228 (1989)

8. T Devadithya, K Chiu, K Huffman, DF McMullen, in Proceedings of the First International Conference on Science and Grid Computing, 2005. The common instrument middleware architecture, overview of goals and implementation (IEEE, Piscataway, 2005), pp. 96-106

9. IM Atkinson, Dd Boulay, C Chee, K Chiu, P Coddington, A Gerson, T King, DF McMullen, R Quilici, P Turner, A Wendelborn, MJ Wyatt, D Zhang, Developing CIMA-based cyberinfrastructure for remote access to scientific instruments and collaborative e-research. CRPIT. 68, 3-10 (2007)

10. R Bramley, K Chiu, T Devadithya, N Gupta, C Hart, JC Huffman, K Huffman, Y Ma, DF McMullen, Instrument monitoring, data sharing, and archiving using common instrument middleware architecture (CIMA). J. Chem. Inf. Mod. 46(3), 1017-1025 (2006)

11. JF Wan, HH Yan, H Suo, F Li, Advances in cyber-physical systems research. KSII Trans. Internet Inf. Sys. 5(11), 1891-1908 (2011)

12. K Chiu, R Bramley, JC Huffman, K Huffman, DF McMullen, Instruments and, Sensors as Web Services. (National Science Foundation of ACl, Arlington, 2003)

13. M Chen, JF Wan, F Li, Machine-to-Machine Communications: Architectures, Standards and Applications. KSII Trans. Internet Syst. 6(2), 480-497 (2012) 
14. JH Shi, JF Wan, HH Yan, H Suo, in 2011 IEEE International Conference on Wireless Communications and Signal Processing (WCSP). A survey of cyber-physical systems (IEEE, Piscataway, 2011), pp. 1-6

15. J Peng, KH Law, in Proceedings of the International Symposium on Earthquake Engineering in the Past and Future Fifty Years. A Reference Data Model for NEESgrid Shake Table Experiments (Harbin, August 2004)

16. M Chen, "Towards smart city: M2M communications with software agent intelligence", Multimedia Tools Appl., pp.1-12, Feb.2012

17. M Chen, S Gonzalez, Q Zhang, VC Leung, Code-centric RFID system based on software agent intelligence. IEEE Intell. Syst. 25(2), 12-19 (2010)

18. M Chen, S Gonzalez, Y Zhang, VC Leung, in Quality of Service in Heterogeneous Networks. Multi-agent itinerary planning for wireless sensor networks (Springer, Heidelberg, 2009), pp. 584-597

19. M Chen, V Leung, SW Mao, T Kwon, M Li, in IEEE International Conference on Communications, 2009. Energy-efficient itinerary planning for mobile agents in wireless sensor networks (IEEE, Piscataway, 2009), pp. 1-5

20. L Zhou, X Wang, W Tu, GM Muntean, B Geller, Distributed scheduling scheme for video streaming over multi-channel multi-radio multi-hop wireless networks. Selec. Areas Commun. IEEE J. 28(3), 409-419 (2010)

21. DucklingTeam, CERC (2009). http://duckling.escience.cn/dct/. Accessed 2 July 2010

22. GRIDCC Project report (2008). http://ec.europa.eu/information_society/ apps/projects/logos/2/511382/080/publishing/readmore/GRIDCC-WP8D8_3-20080201-06-INF-Final_Report.pdf. Accessed 10 June 2009

23. AS McGough, A Akram, L Guo, M Krznaric, L Dickens, D Colling, J Martyniak, R Powell, P Kyberd, C Kotsokalis, in Proceedings of the 2nd Workshop on Workflows in Support of Large-scale Science. GRIDCC: real-time workflow system (ACM, New York, 2007), pp. 3-12

24. E Christensen, F Curbera, G Meredith, S Weerawarana, Web Services Description Language (WSDL) 1.1. (World Wide Web Consortium, Cambridge, 2001)

25. Z Huang, L Gu, B Du, C He, in Proceedings of 2004 IEEE International Conference on Services Computing. Grid resource specification language based on XML and its usage in resource registry meta-service (IEEE, Piscataway, 2004), pp. 467-470

26. D Brickley, RV Guha, RDF Vocabulary Description Language 1.0: RDF Schema (World Wide Web Consortium, Cambridge, 2004)

27. V Tosic, B Pagurek, K Patel, "WSOL - a language for the formal specification of classes of service for web services". (International Conference on Web Services, Las Vegas, Nevada, USA, June 2003)

28. V Tosic, K Patel, B Pagurek, in Web Services, E-Business, and the Semantic Web. WSOL-web service offerings language (Springer, Heidelberg, 2002), pp. 57-67

29. D Martin, M Burstein, O Lassila, M Paolucci, T Payne, S Mcllraith, Describing Web services using OWL-S and WSDL. DAML-S Coalition working document. [http://www.daml.org/services/daml-s/0.7/daml-s-wsdl.html] Accessed 13 Aug 2002

30. A Matoussi, R Laleau, A Survey of Non-functional Requirements in Software Development Process. (University of Paris, Paris, 2008)

31. L Li, I Horrocks, A software framework for matchmaking based on semantic web technology. Int. J. Electron. Commerce. 8(4), 39-60 (2004)

32. M Paolucci, T Kawamura, TR Payne, K Sycara, in The Semantic Web-ISWC 2002. Semantic matching of web services capabilities (Springer, Heidelberg, 2002), pp. 333-347

33. N Srinivasan, M Paolucci, K Sycara, Semantic web service discovery in the OWL-S IDE. Proc. 39th Annual IEEE Hawaii Int. Conf. Syst. Sci. 6, 109b (2006)

34. D Ardagna, B Pernici, Adaptive service composition in flexible processes. Softw. Eng. IEEE Trans. 33(6), 369-384 (2007)

35. $\mathrm{B} X \mathrm{Xu}, \mathrm{T} \mathrm{Li}, \mathrm{Z} \mathrm{Gu}, \mathrm{G}$ Wu, in The 8th IEEE International Conference on E-Commerce Technology, 2006 and The 3rd IEEE International Conference on Enterprise Computing, E-Commerce, and E-Services. SWSDS: Quick web service discovery and composition in SEWSIP (IEEE, Piscataway, 2006), pp. $71-71$

36. IB Arpinar, R Zhang, B Aleman-Meza, A Maduko, Ontology-driven web services composition platform. Inf. Syst. E-Business Manage. 3(2), 175-199 (2005)

37. M Tian, A Gramm, H Ritter, J Schiller, in Proceedings of the 2004 IEEE/WIC/ACM International Conference on Web Intelligence, IEEE Computer Society. Efficient selection and monitoring of QoS-aware web services with the WS-QoS framework (IEEE, Piscataway, 2004), pp. 152-158
38. A Soydan Bilgin, MP Singh, in Proceedings of IEEE International Conference on Web Services, 2004. A DAML-based repository for QoS-aware semantic web service selection (IEEE, Piscataway, 2004), pp. 368-375

39. L Sha, G Shaozhong, C Xin, L Mingjing, A QoS based web service selection model. IFITA. 3, 353-356 (2009)

40. F Qiqing, P Xiaoming, L Qinghua, $\mathrm{H}$ Yahui, A global QoS optimizing web services selection algorithm based on MOACA for dynamic web service composition. IFITA. 1, 37-42 (2009)

41. AJS Cardoso, Quality of service and semantic composition of workflows. PhD thesis. (University of Georgia Athens, Georgia, 2002)

42. M Kerrigan, in Proceedings of the 2006 ACM Symposium on Applied Computing. Web service selection mechanisms in the web service execution environment (WSMX) (ACM, New York, 2006), pp. 1664-1668

43. C Zhou, LT Chia, BS Lee, in Proceedings of IEEE International Conference on Web Services, 2004. DAML-QoS ontology for web services (IEEE, Piscataway, 2004), pp. 472-479

44. Em Maximilien, MP Singh, A framework ontology for dynamic web services selection. Int. Comp. IEEE. 8(5), 84-93 (2004)

45. L Sha, G Shaozhong, C Xin, L Mingjing, A qos based web service selection model. IFITA. 3, 353-356 (2009)

46. S Ali, M Zeeshan, in 2012 IEEE Wireless Communications and Networking Conference (WCNC). A utility based resource allocation scheme with delay scheduler for LTE service-class support (IEEE, Piscataway, 2012), pp. 1450-1455

doi:10.1186/1687-1499-2013-181

Cite this article as: Zhang et al:: A novel multimedia device ability matching technique for ubiquitous computing environments. EURASIP Journal on Wireless Communications and Networking 2013 2013:181.

\section{Submit your manuscript to a SpringerOpen ${ }^{\circ}$ journal and benefit from:}

- Convenient online submission

Rigorous peer review

- Immediate publication on acceptance

- Open access: articles freely available online

- High visibility within the field

- Retaining the copyright to your article

Submit your next manuscript at $>$ springeropen.com 